\title{
I Can, I Do, I Am: The Narrative Differentiation of Self-Efficacy and Other Self-Evaluations while Adapting to Bereavement
}

\author{
Jack J. Bauer \\ Northwestern University \\ and \\ George A. Bonanno \\ Teachers College, Columbia University \\ Published online November 2, 2001
}

\begin{abstract}
Research has established a strong link between self-efficacy and psychological health, particularly during times of crisis. Theory on self-efficacy posits a difference between the ability to do something and actually doing it. In this study, personal narratives of people whose spouses had died during midlife were coded by distinguishing self-evaluations of abilities ("what I can do or be") from self-evaluations of actual behaviors ("what I do") and characteristics ("what I am"). The narratives came from interviews at 6 months post-loss. The narrative self-evaluation variables were compared to separate clinical interview measures of grief at 6, 14, and 25 months post-loss. As predicted, narrative descriptions of self-efficacy (i.e., overt evaluations of one's abilities) predicted less grief over time, even when controlling for perceptions of actually doing well and being good. Furthermore, self-efficacy appeared to neutralize the ill effects of negatively evaluating one's behaviors but not one's characteristics. Findings are interpreted in terms of identity construction and personal meaning making during times of major life change, highlighting selfefficacy's distinct role in both narrative thinking and psychological adaptation.

() 2001 Elsevier Science
\end{abstract}

Research has consistently shown a relationship between self-efficacy and psychological health, particularly during times of crisis and adjustment

We thank Dan McAdams, April Sakaeda, Larissa Siegel, and two anonymous reviewers for their insightful contributions to this study.

Address correspondence and reprint requests to Jack Bauer, Foley Center for the Study of Lives, School of Education and Social Policy, Northwestern University, 2115 North Campus Drive, Evanston, IL 60208, or George A. Bonanno, Department of Counseling and Clinical Psychology, Box 218, 525 West 120th Street, Teachers College, Columbia University, New York, NY 10027. E-mail: jackbauer@ northwestern.edu or gab38@columbia.edu. 
(Bandura, 1997; Maddux \& Lewis, 1995). Theory on self-efficacy posits the distinction between the ability to do something and actually doing it (Bandura, 1977). Yet research has not addressed how people perceive this distinction conceptually in the course of everyday thinking and narration, let alone how this perceived distinction relates to psychological health during times of crisis. In this study, we examined the narrative interviews of people who had recently lost a spouse during midlife. We coded these narratives for types of self-evaluation, making distinctions between evaluations of one's own abilities (i.e., self-efficacy) and evaluations of one's own behaviors and characteristics. We predicted, among other things, that making overt narrative evaluations of self-efficacy (e.g., "I can do things well'") would correspond with psychological health during the 2 years following the loss, over and beyond making other related self-evaluations (e.g., "I do things well,", "I'm a good person').

A constellation of constructs revolving around self-efficacy has been paired with psychological health, well-being, and adjustment to major life change (Bandura, 1977, 1997; Diener, 1984; Diener, Suh, Lucas, \& Smith, 1999; Folkman, 1984; Maddux \& Lewis, 1995; Ryff \& Singer, 1998; Taylor \& Brown, 1988, 1994). These constructs address different facets of selfefficacy such as a sense of feeling capable, strong, or in control-essentially the perception that one can do or be something that is personally desirable (Bandura, 1977; Baumeister, 1991). These constructs have labels such as control, mastery, abilities, and skills. The constructs have been measured as perceived abilities for successful actions in general (Diener \& Fujita, 1995; Florian, Mikulincer, \& Taubman, 1995; Lachman \& Weaver, 1998; Robitschek \& Kashubeck, 1999) or in specific contexts such as perceived abilities for personal projects (McGregor \& Little, 1998), academics (Bandura, Pastorelli, Barbaranelli, \& Caprara, 1999; Manstead \& van Eekelen, 1998), finding housing (Epel, Bandura, \& Zimbardo, 1999), coping with difficult decisions (Major, Richards, Cooper, Cozzarelli, \& Zubek, 1998), and making and maintaining a variety of changes in one's life (Bandura, 1997).

In this study, we distinguished the perception of an ability to do or be something from the perception of actually doing or being it. In outlining a general framework for research on self-efficacy, Bandura (1977) distinguished the ability to do something both from the act of doing it and from the evaluation of the act. This can be a subtle distinction, especially in terms of social-cognitive perceptions. Abilities and behaviors are closely linked in everyday thinking. For example, research on the fundamental attribution error and the self-serving bias has shown that people tend to infer from even a single behavior that someone else or the self has certain dispositions and abilities (Langer \& Roth, 1975; Ross, Amabile, \& Steinmetz, 1977). Some research has differentiated self-efficacy from the perceived control of behaviors in predicting certain behaviors (Armitage \& Conner, 1999; Manstead \& 
van Eekelen, 1998), and other research has controlled for personality variables in relating self-efficacy to psychological health (Lachman \& Weaver, 1998; Robitschek \& Kashubek, 1999). But to our knowledge, no research has addressed how people distinguish evaluations of their own abilities from evaluations of what they have done (behaviors) and who they are (characteristics), let alone how this distinction relates to psychological health. The distinction may be especially important during times of crisis because at these times the view that one could possibly make things go well might be the individual's predominant mechanism for coping with difficult circumstances (Bandura, 1977; Folkman, 1984).

To study this distinction as it might occur in the course of everyday thinking during times of crisis, we examined the personal narratives of people undergoing conjugal bereavement. Briefly, we coded these narratives for two types of self-evaluation: self-evaluations involving explicit references to abilities (i.e., self-efficacy) and self-evaluations involving references to actual behaviors and characteristics but not explicitly to abilities. All self-evaluations, including self-efficacy, involved an overt, affectively valenced description of the self, that is, an evaluation of the self either doing something (a behavioral self-evaluation) or being something (a characterological selfevaluation) (see Appendix). Self-efficacy involved all of the criteria for selfevaluations plus an overt reference to abilities. For example, "I made her feel better' is a self-evaluation (of a behavior) without explicit reference to abilities, whereas "I was able to make her feel better" explicitly refers to abilities and, therefore, would be coded for self-efficacy. (The coding system is explained more fully under Method.) In his review of empirical work on how people construct broader meanings in life, Baumeister (1991; see also Baumeister \& Newman, 1994) made theoretical distinctions among selfefficacy, the justification of one's behaviors, and self-worth. These distinctions served as the initial framework for the current study's operational definitions.

The death of a spouse during midlife typically demands that the surviving spouse reorganize his or her life considerably, from daily roles to major life goals (Parkes \& Weiss, 1983). Central to such reorganization is a narrative process of self-evaluation that balances perceptions of what one values, what one does, what one is, and what one can do and be (Baumeister, 1991; McAdams, 1993). The death of a spouse during midlife occurs at a time when many of the couple's roles in daily life are created and established in terms of each other as well as at a time when many long-range plans are under way but not completed (Parkes \& Weiss, 1983; Wortman \& Silver, 1990). The untimely death often leaves the bereaved spouse with a sense of lost identity or a feeling that part of the self is missing, both of which are closely tied with the loss of knowing "what to do" or "how to be" in daily roles (Parkes \& Weiss, 1983). In choosing new and adaptive courses of action after the death (or after major crises in general), the individual must first 
feel able to take on those new actions and ways of being (Folkman, 1984). Bereaved individuals have been shown to have lower levels of self-efficacy than nonbereaved individuals (Arbuckle \& de Vries, 1995; Stroebe \& Stroebe, 1993), so a sense of self-efficacy may be especially helpful in thinking about and planning one's life after the loss in an adaptive fashion. However, research has yet to explore self-efficacy's unique role among self-evaluations in predicting individual differences in adjustment to bereavement.

At this point, we should comment on narrative methodology in the context of our main topics. In the current study, we did not ask participants to assess specifically their perceptions of control, mastery, or other efficacy-related constructs. Instead, we asked participants to talk about their life with their deceased spouse. We then coded the spontaneously generated references to personally meaningful abilities, behaviors, and characteristics. Although the questionnaire approach has produced volumes of stimulating and useful research, a narrative approach is more applicable to questions on how people distinguish among various forms of self-evaluation in everyday thinking and social interaction (Bauer \& Bonanno, 2001). The conceptual distinction between abilities and behaviors is subtle, as are other dimensions of personhood, yet people do make such distinctions. Furthermore, they do so rapidly and perhaps without awareness in the course of thinking and conversation. Thus, narratives tap into underlying cognitive and social-cognitive processes that have implications for both self-understanding and psychological health (Singer \& Salovey, 1993). Distinctions in this interpretive process, such as the perceived difference between abilities and actions, are at the heart of the current study's concerns, making narratives the medium of choice for our interests. Yet, narrative inquiry offers more than an epistemologically suitable form of data and method of research. By investigating linguistic distinctions such as "I can do", versus "I do," we aim to better understand the structure of the personal narrative itself, that is, the elements of people's life stories.

Narrative interviews with participants were conducted approximately 6 months after the death of the spouse. The interviews were transcribed and coded for the self-efficacy and other self-evaluation variables. These narrative variables were compared to clinical interview measures of grief at 6 , 14, and 25 months post-loss (see Method). We made four main predictions for the study.

1. Explicit references to self-efficacy would be distinct from references to behavioral and characterological self-evaluations. With this first prediction, we aimed to assess the degree to which different yet related speech patterns (e.g., I can, I do, I am) covaried. Establishing distinctions in these patterns would mark an essential first step toward understanding how differences in perceptions of abilities, behaviors, and characteristics related to levels of psychological health. 
2. References to self-efficacy would predict lower grief levels over time. As mentioned earlier, nonnarrative measures of self-efficacy have shown a consistent relationship with psychological health. The same should be true for narrative measures of self-efficacy during conjugal bereavement.

3. The relationship between self-efficacy and grief would be independent of the relationship between other self-evaluations and grief. This prediction combined the principles of the first two predictions. Like the first prediction, this one marked a departure from nonnarrative methods by distinguishing self-efficacy from other self-evaluations as they are made in everyday thinking and conversation rather than being artificially teased out by measures specific to different types of self-evaluation. Like the second prediction, this prediction linked self-efficacy and psychological health, although it controlled for behavioral and characterological self-evaluations.

4. Self-efficacy would moderate the relations between behavioral and characterological self-evaluations and grief. This final prediction was based on the complex proposition that people not only distinguish abilities, behaviors, and characteristics but also weigh the three conjointly when forming broader self-evaluations and plans for action (Bandura, 1977; Folkman, 1984).

\section{METHOD}

\section{Participants}

Participants were recruited from the San Francisco Bay area via newspaper advertisements, posted notices, and referrals from medical and religious organizations. Participants were required to have experienced the death of a spouse within the previous 3 to 6 months and to discuss their recent experience so that "more could be learned about the grieving process from a scientific standpoint." In addition, they were required to be between 21 and 55 years of age, to have been married and living with the deceased for a minimum of 3 years preceding the death, and not to have experienced any serious mental or physical disorders, alcohol or other substance abuse, or binge eating during that time. Participants were paid $\$ 10$ per hour. Interview transcripts were available for 69 participants. These participants ranged in age from 24 to 55 years $(M=47.4, S D=8.1)$. Also, $67 \%$ were female, $80 \%$ were Caucasian, $11 \%$ were African American, and $9 \%$ were of another ethnicity. Participants, on average, were married to the deceased for 15.8 years $(S D=$ $11.2)$, had 15.5 years of education $(S D=2.0)$, and had a median family income of $\$ 52,000$.

\section{Procedure}

Overview. Information on demographics and potential moderators of the self-evaluation-grief relationship was obtained via self-report questionnaires 
between 3 and 6 months post-loss. A structured clinical interview was conducted at approximately 6 months post-loss ( $M=5$ months 18 days) to assess grief. These interviews were assessed for grief, a global measure of psychological functioning in relation to the loss. The longitudinal grief measures were used as the primary dependent variable. A semistructured, openended narrative interview was conducted approximately 2 weeks later $(M=$ 17 days). Narrative interviews asked for the participant's description of the relationship with the spouse. The narratives were transcribed and coded for patterns of self-evaluation, which were used as the primary independent variables (keeping in mind the correlational nature of the study).

Structured clinical interview. In the current study, as in previous studies from the larger bereavement project, grief was operationally defined as the total disruption in daily functioning that could be directly attributed to the loss (Bonanno \& Keltner, 1997; Bonanno, Keltner, Holen, \& Horowitz, 1995). The interview measure consisted of 30 unique grief items such as intrusive memories or images of the deceased and unusual difficulty in being emotionally available to significant others. The interviewers, three doctoral candidates in clinical psychology, were blind to the study's goals and hypotheses and made presence-absence judgments for each grief item. All interviews were videotaped, with a randomly selected set of 25 used for interrater reliability $(\kappa=.78)$. Three different forms of convergent validity were established and have been reported elsewhere (Bonanno et al., 1995).

Semi-structured narrative interview. Participants were informed that the interview would be videotaped. Each participant was seated in a comfortable chair facing a similar unoccupied chair in an 8- by 10-foot room with two wall-mounted cameras. The participant was informed about and fitted for physiological measures during the interview and was then left alone in the room for $10 \mathrm{~min}$ to gather baseline physiological data (reported elsewhere [Bonanno et al., 1995]). An interviewer then entered the room and read a prepared script informing the participant that he or she would be asked to speak for 18 min about important persons in the participant's life. The current study examines the 6-min segment of the interview in which the participant responded to the prompt, "Please tell me about your relationship with [deceased person's name]." The participant was told that the interviewer would keep track of time and that he or she need not feel pressure about running out of things to say. The interviewer spoke only to ask clarifying questions and did not lead the narrative content in any way.

Potentially confounding variables. Three measures were considered as possible confounds of the self-evaluation-grief relationship: (a) the Dyadic Adjustment Scale (DAS), which measured recollections of marital compatibility and adjustment (Bonanno et al., 1995; Spanier, 1976); (b) perceived social support (Bonanno et al., 1995; Kessler, Kendler, Heath, Neale, \& Eaves, 1992; Kessler \& MacLeod, 1985); and (c) a verbosity variable, calcu- 
lated by tallying each participant's total number of narrative units (described next).

\section{Narrative Measurement}

Transcription of the narrative units. The narrative interviews were transcribed from audiotaped recordings using standards developed for psychotherapy sessions (Mergenthaler \& Stinson, 1992; Stinson, Milbrath, Reidbord, \& Bucci, 1994). Judges segmented each transcript into narrative units (NUs) based on their intuitive understanding of the natural boundaries of a complete thought or idea (Butterworth, 1975; Stinson et al., 1994). The judges' ratio of agreement on NU boundaries was .81 (calculated by summing the number of NU markers on which judges agreed, multiplying that number by 2 , and then dividing by the total number of NU markers coded). The 69 interview narratives had a mean of 36.6 NUs each $(S D=15.3)$.

Coding for self-evaluations in general. Narrative transcripts were coded according to a detailed coding system for narrative self-evaluation (Bauer \& Bonanno, 2001). The first author (Jack Bauer) and an advanced graduate student in psychology coded the transcripts. All discrepancies were discussed and settled mutually. A self-evaluation was operationally defined as a selfdescription modified by an overt personal opinion or value. First, the selfevaluation needed to refer to the narrator as the person being evaluated, typically by use of a first-person pronoun (e.g., I, we, me, my, our) (see Appendix). The criteria for the evaluative aspect of self-evaluations were stringent in an effort to find only those self-descriptions that were likely to hold meaning for the individual. All self-evaluations were coded along three dimensions: (a) valence (positive or negative), (b) levels of context (behavioral or characterological), and (c) efficacy (presence or absence of references to abilities, strength, or control). Each NU was coded for the presence or absence of each type of self-evaluation, resulting in the presence of six possible self-evaluations (positive behavioral, negative behavioral, positive characterological, negative characterological, positive efficacy, or negative efficacy). Valence was determined by whether the participant evaluated the action or characteristic as good or bad. A participant's self-description was considered to be evaluated only when it was modified by value-laden adjectives and adverbs (e.g., great, horrible, enjoyable, poorly), by value-laden consequences (i.e., results of an action or characteristic that elicits affect), or by relevant expectations or motivations (i.e., consequences that are evaluated by what the participant said he or she wanted, ought to do, or tried to do). Coders found that the valence of a self-evaluation was almost always obvious once a self-description was determined to be evaluative. Interrater reliability for the valence of self-evaluations was .98 using the kappa statistic. Levels of context were more difficult to determine. The primary distinction between behavioral and characterological levels of meaning was the use of 
the verbs doing versus being, respectively. Behavioral self-evaluations (i.e., "what one does") were doing based (e.g., making, playing, working, going, talking, learning) (see Appendix). Characterological self-evaluations (i.e., "what one is") were being based (e.g., are, was, becoming, existing). The difficulty in distinguishing behavioral from characterological self-evaluations typically lay in verbs expressing "having." However, because having implies ownership and, thus, reflects more permanent qualities of the self (Bauer \& Bonanno, 2001; Cantor, 1990; James, 1890/1950), we coded all having-based self-evaluations as characterological, thereby pairing havingbased and being-based self-evaluations. Interrater reliability for behavioral and characterological self-evaluations, using the kappa statistic, was .76. Convergent and discriminant validity was established for distinguishing evaluative and nonevaluative self-evaluations using a multitrait-multimethod matrix (Campbell \& Fiske, 1959) in conjunction with another measure of narrative self-description (reported in Bauer \& Bonanno, 2001).

Coding specifically for self-efficacy. Efficacious self-evaluations (i.e., "what one can do" or "what one can be") were ability based, involving the sense of feeling capable, strong, or in control. Efficacious self-evaluations were also called simply "self-efficacy." Inefficacious self-evaluations (i.e., "what one can't do" or "what one can't be") were inability based, involving the sense of feeling incapable, weak, or controlled by an undesirable or unknown force. Inefficacious self-evaluations were also called "selfinefficacy." Coding for ability-based and inability-based self-evaluation involved several criteria. First, all of the criteria for a self-evaluation described earlier must have been met. Thus, all statements of self-efficacy were selfevaluations, although not all self-evaluations involved statements of selfefficacy.

Second, the participant must have made explicit reference to either his or her own ability (or strength) or his or her own inability (or weakness). The verb can and the adjective able were primary indicators of a sense of efficacy (see Appendix). Other common key words were strength and control. However, as mentioned in the introduction, abilities were not inferred from the mere evaluation of successful behaviors. For example, the positive behavioral (i.e., doing-based) self-evaluation, "I golfed well,", suggests an ability to golf but does not overtly mention that ability (in contrast to "I was able to golf well"'). This is a subtle distinction in narratives given that people form a close connection between abilities and behaviors, between abilities and other characteristics, and between abilities and possessions. When a person says, "I got a promotion at work," the listener typically assumes that the speaker has the ability to do good work. Yet when one fails at a task (particularly if that person is the self), one is likely to attribute failure to external forces, particularly if that person tends to adapt well to difficult circumstances (Taylor \& Brown, 1988). Thus, only explicit statements of 
abilities or control were coded for efficacy or inefficacy (e.g., "I'm an able parent," "I can golf well," "I feel like I have no control").

Third, the result of the ability in question must have been desirable from the participant's perspective. (In the case of an inability, the ability that is lacking must be considered desirable from the participant's perspective.) In other words, the perception of an ability to do something bad does not facilitate a sense of efficacy, although it does not facilitate a sense of inefficacy either. Furthermore, the inability to do something that one does not find desirable tends not to elicit a sense of inefficacy. The coding system reflected each of these conditions.

Fourth, the ability in question must have been described (or generally accepted) as possible to exercise within given environmental constraints. A sense of inefficacy was not coded if a person described an inability to do something impossible. For example, the phrases, "There was nothing I could do to help her but she was terminally ill" and "I couldn't do what I wanted but I did all I could,' involved situations that were beyond abilities that the person deemed reasonable. Inefficacy does not emerge if the person perceives the environmental conditions as impervious to human abilities (Bandura, 1977). Such statements were not coded for negative efficacy. However, the statement, "I couldn't do what I wanted to do,' without other qualifying statements, would be coded as negative efficacy.

Fifth, the ability in question must have been especially or uniquely useful within a given situation or purpose. This rule excludes ordinary abilities such as being able to tie one's shoes and includes particularly useful abilities (e.g., "I was able to provide a good life for her," 'We weren't able to see how important communication is for kids"), unless the person states explicitly that a seemingly ordinary ability is personally meaningful.

As a final note, people frequently refer to the degree of difficulty of some activity (e.g., "I've had a relatively easy time of things"). The ease or difficulty of a task is reflective of ability (which is always relative to the perceived challenges of the task). However, being able to succeed at easy tasks does not necessarily produce a sense of efficacy, and being unable to succeed at difficult tasks does not necessarily produce a sense of inefficacy (Bandura, 1977). Furthermore, we found that people tended not to use a first-person pronoun when talking about the difficulty of doing something (e.g., "It's been hard adjusting to being single" instead of "I've had a hard time adjusting to being single"'). Statements such as the former, due to the lack of an explicit first-person pronoun, were not coded as self-evaluations in any form. In this study, we also did not code statements such as "I've had a hard time" (whether using "easy" or "hard") in terms of efficacy. This more conservative stance toward coding the presence of efficacy or inefficacy may be expanded in the future to include these fuzzier areas. Interrater reliability for positive and negative efficacy, using the kappa statistic, was .87 . 
Calculating the variables. Each self-evaluation variable was computed for each participant by adding the total number of NUs containing that selfevaluation. Thus, we measured six types of self-evaluations: self-efficacy (i.e., ability based), self-inefficacy (i.e., inability based), positive behavioral, negative behavioral, positive characterological, and negative characterological. Only one type of self-evaluation could be coded per NU. This rule allowed the coding system to capture different levels of context without reflecting the tendency of some people to provide a rapid string of variations on the same self-evaluation. By measuring self-evaluations in terms of frequency counts, we addressed each participant's tendency to make certain types of self-evaluation. The frequency with which people mention particular topics or themes in life stories is one way of demonstrating the degree to which those topics or themes hold personal meanings for the individuals (McAdams, 1993). To control for the possibility that the tendency to talk a lot might alter the self-evaluation-grief relationship, we created a verbosity variable for each participant by adding the total number of NUs made.

\section{RESULTS}

\section{Overview}

First, we consider descriptive statistics, which have implications for how we examined the variables. Second, we consider intercorrelations among the narrative variables, primarily to examine the distinction between self-efficacy and other self-evaluations. Then, we review the relationship between self-efficacy and grief over time. All regression analyses involving grief over time (i.e., grief at 6, 14, and 25 months post-loss) involve longitudinally weighted grief variables, which are explained later. After examining selfefficacy and grief over time, we turn to the relationships between the nonefficacy forms of self-evaluation (e.g., positive behavioral self-evaluation, positive characterological self-evaluation) and grief over time. These analyses involve curvilinear relationships, which are explained. We then examine four multiple-regression models that examine the relationship between self-efficacy and each of the other four types of self-evaluation in predicting grief over time. Finally, we consider potential confounds.

\section{Descriptive Statistics}

During the 6-min narrative segment, a total of 22 participants made statements of self-efficacy (see Table 1). Of those, 17 participants made 1 abilitybased self-evaluation, 3 participants made 3 ability-based self-evaluations, 1 participant made 5, and 1 participant made 6 . Only 1 participant made an inability-based self-evaluation, precluding self-inefficacy from further analyses. These results led us to study self-efficacy as a dichotomous variable, comparing those who made any statement of self-efficacy to those who made 
TABLE 1

Descriptive Statistics

\begin{tabular}{lcccrr}
\hline \multicolumn{1}{c}{ Variable } & Mean & $\begin{array}{c}\text { Standard } \\
\text { deviation }\end{array}$ & Minimum & Maximum & $n$ \\
\hline Self-efficacy & 0.52 & 1.07 & 0 & 6 & 22 \\
Self-inefficacy & 0.01 & 0.00 & 0 & 1 & 1 \\
Positive behavioral self-evaluation & 2.17 & 1.77 & 0 & 8 & 58 \\
Negative behavioral self-evaluation & 0.28 & 0.51 & 0 & 2 & 17 \\
Positive characterological self-evaluation & 3.22 & 2.05 & 0 & 11 & 65 \\
Negative characterological self-evaluation & 0.64 & 0.87 & 0 & 3 & 30 \\
Grief at 6 months post-loss & 9.88 & 5.81 & 0 & 23 & 69 \\
Grief at 14 months post-loss & 6.35 & 5.45 & 0 & 21 & 57 \\
Grief at 25 months post-loss & 4.56 & 3.78 & 0 & 13 & 45 \\
\hline
\end{tabular}

Note. Total $N=69 . n$ represents the number of participants making at least one self-evaluation of each type (except for grief variables, where $n$ represents the number of participants at each time of measurement).

no such statement. Table 1 also presents a profile of the other types of selfevaluation. Both positive behavioral and positive characterological selfevaluations exhibited normal distributions. Both negative behavioral and negative characterological self-evaluations exhibited positively skewed distributions, which led us to convert these distributions into ordinal-level groups (described later). Mean grief scores decreased from 6 to 14 months post-loss, $t(1,56)=4.49, p<.001$, and from 14 to 25 months postloss, $t(1,42)=2.67, p=.01$. This decline in grief scores conforms to longitudinal symptom patterns found in other studies (Bonanno \& Kaltman, 1999).

\section{Relations between Self-Evaluation Variables}

We ran intercorrelations between the self-evaluation variables to test whether narrative patterns of self-efficacy were distinct from other patterns of self-evaluation. These correlation coefficients appear to the right of the boxed area in Table 2. Pearson correlation coefficients are reported for comparisons between positive behavioral and positive characterological selfevaluations (and between those two variables and grief, as is reported below). Spearman correlation coefficients are reported for any comparisons involving self-efficacy, negative behavioral self-evaluation, and negative characterological self-evaluation because these variables involved skewed distributions. Self-efficacy, which by definition was either a behavioral or a characterological self-evaluation modified by a reference to abilities, correlated only with positive behavioral self-evaluation, Spearman $r=.26, p<$ .05. In other words, those who made ability-based self-evaluations also made significantly higher numbers of positive behavioral self-evaluations, $t(1$, $67)=2.28, p<.05$. Self-efficacy did not correlate significantly with any of 
TABLE 2

Correlations of Self-Efficacy, Other SEs, and Grief over Time

\begin{tabular}{|c|c|c|c|c|c|c|c|}
\hline Variable & 1 & 2 & 3 & 4 & 5 & 6 & 7 \\
\hline $\begin{array}{l}\text { 1. Grief at } 6 \text { months } \\
\text { 2. Grief at } 14 \text { months } \\
\text { 3. Grief at } 25 \text { months }\end{array}$ & $\begin{array}{l}.52 * * * \\
.61 * * *\end{array}$ & $.71 * * *$ & & & & & \\
\hline $\begin{array}{l}\text { 4. Self-efficacy } \\
\text { 5. Positive behavioral SE } \\
\text { 6. Negative behavioral SE } \\
\text { 7. Positive characterological SE } \\
\text { 8. Negative characterological SE }\end{array}$ & $\begin{array}{l}-.18 \\
-.15 \\
-.13 \\
-.09 \\
-.03\end{array}$ & $\begin{array}{l}-.40^{* *} \\
-.30^{*} \\
-.15 \\
.06 \\
.12\end{array}$ & $\begin{array}{l}-.50 * * * \\
-.42 * * \\
-.18 \\
-.15 \\
.16\end{array}$ & $\begin{array}{l}.26^{*} \\
.12 \\
.16 \\
.15\end{array}$ & $\begin{array}{l}.11 \\
.36^{* *} \\
.07\end{array}$ & $\begin{array}{l}.05 \\
.23\end{array}$ & .13 \\
\hline
\end{tabular}

Note. SE, self-evaluations. Correlations between narrative self-evaluation variables and grief variables appear within the boxed area.

$$
\begin{aligned}
* p & <.05 . \\
* * p & <.01 . \\
* * * p & <.001 .
\end{aligned}
$$

the three other forms of self-evaluation: positive characterological, negative behavioral, or negative characterological. Positive behavioral and positive characterological self-evaluations were correlated significantly, $r=.36, p<$ .01. Negative behavioral and negative characterological self-evaluations were not significantly correlated.

\section{Self-Efficacy and Grief over Time}

Correlation coefficients between narrative self-evaluation variables and grief variables appear within the boxed area in Table 2. Self-efficacy (measured at 6 months post-loss) was correlated significantly and inversely with grief at 14 months post-loss, $r=-.40, p<.01$, and at 25 months post-loss, $r=-.50, p<.001$ (see Table 2). To make predictions of grief over time, we created longitudinally weighted grief variables that we regressed on the self-evaluation variables (Judd \& McClelland, 1989). One longitudinal grief variable was created by weighting grief at 6,14 , and 25 months post-loss to test for main "effects" (keeping in mind the correlational nature of the study). Two additional longitudinal grief variables were created by weighting grief over time with linear and curvilinear (quadratic) contrast codes, which enabled the testing of interactions between self-evaluation variables and time in predicting grief. These regression models were the statistical equivalent of a repeated-measures analysis of variance (ANOVA), but with allowances for specific 1- $d f$ tests within multiple-regression models. Regressing longitudinally weighted grief on self-efficacy, we found that participants who made reference to abilities when making self-evaluations had significantly lower grief levels over time than did those who did not refer to abilities, $t(1,41)=$ $-2.68, p=.01$, standardized beta $=-.39$, accounting for $13 \%$ (adjusted 
TABLE 3

Mean Grief Scores for Participants Referring and Not Referring to Self-Efficacy

\begin{tabular}{cccc}
\hline \multicolumn{1}{c}{ Group } & 6 months & 14 months & 25 months \\
\hline Self-efficacy $(n=13)$ & $8.15(5.84)^{*}$ & $3.23(2.71)^{*}$ & $2.00(1.47)^{*}$ \\
Non-self-efficacy $(n=30)$ & $10.37(5.77)^{*}$ & $7.87(6.02)^{*}$ & $5.93(3.83)^{*}$ \\
\hline
\end{tabular}

Note. Mean grief scores.

$* p=.01$.

$R^{2}$ ) of the variance of grief over time (see Table 3 for mean differences). ${ }^{1}$ The interaction of self-efficacy group by time was not significant in predicting grief $(p>.20)$. In other words, participants who made explicit statements of self-efficacy had lower levels of grief over time than did those who made no such statements, although grief levels decreased over time at the same rate for both groups.

\section{Behavioral and Characterological Self-Evaluations and Grief over Time}

The total number of positive behavioral self-evaluations was significantly and inversely correlated with grief at 14 months post-loss, $r=-.30, p<$ .05 , and at 25 months post-loss, $r=-.42, p<.01$ (see Table 2). None of the remaining types of self-evaluation-negative behavioral, positive characterological, or negative characterological—correlated significantly with grief at any measurement time. Similarly, in a regression with longitudinally weighted grief, we found that the tendency to make positive behavioral selfevaluations predicted significantly lower levels of grief over time, $t(1,41)=$ $-2.38, p<.05$, standardized beta $=-.35$, accounting for $10 \%$ (adjusted $R^{2}$ ) of the variance of grief over time. We found no significant interaction of positive behavioral self-evaluation by time in predicting grief $(p>.70)$. Overall, these models were the statistical equivalent of a repeated-measures ANOVA except that they allowed for the use of a continuous variable to predict grief (Judd, McClelland, \& Smith, 1996).

Although neither of the negative self-evaluation variables correlated linearly with grief, we did find curvilinear relationships. Elsewhere, we reported that negative self-evaluation in general held an optimal-level relationship with longitudinal grief such that participants making one negative self-evaluation in the 6-min interview had lower grief levels over time than did those making either none or more than one (Bauer \& Bonanno, 2001). In other

${ }^{1}$ Group $n$ s reported in Table 3 represent only those participants who took part in all three assessments of grief. Participants who continued in the study and those who dropped out did not differ significantly in mean levels of 6-month grief or in mean frequencies of any selfevaluation variable. 
words, there were three levels of frequency for making negative self-evaluations: zero negative self-evaluations $(n=32)$, one negative self-evaluation $(n=22)$, and two or more negative self-evaluations $(n=15)$. The group that made one negative self-evaluation had the lowest levels of grief over time. We found, in the current analysis, that the same optimal-level relationship with longitudinal grief held for both negative behavioral and negative characterological self-evaluation. To arrive at this, we first created linear and curvilinear (quadratic) contrast codes for both forms of negative selfevaluations: negative behavioral self-evaluation and negative characterological self-evaluation. We then created regression models of longitudinally weighted grief on (a) linear and quadratic contrasts of negative behavioral self-evaluation and (b) linear and quadratic contrasts of negative characterological self-evaluation. We found that (a) the quadratic contrast of negative behavioral self-evaluation predicted grief significantly, $t(1,40)=-1.97$, $p=.05$, standardized beta $=-.45$, and $(\mathrm{b})$ the quadratic contrast of negative behavioral self-evaluation predicted grief significantly, $t(1,40)=-2.81$, $p<.01$, standardized beta $=-.43$. In other words, the optimal level of negative self-evaluation held whether considering behavioral or characterological self-evaluations. Participants who made one negative selfevaluation (whether behavioral or characterological) had lower grief levels over time than did those who made either none or more than one. None of the group by time interactions predicted grief significantly $(p s>.10)$. We add that these interpretations are made with caution given that negative selfevaluations were in low frequencies, particularly when considering the behavioral and characterological types separately. Still, these findings enabled us to address further questions, which we review next, on the interaction of distinct narrative self-evaluations of abilities, behaviors, and characteristics in relation to psychological health during bereavement.

\section{Joint Predictions of Grief}

Next, we created four multiple-regression models to determine how selfefficacy and other self-evaluations (and their interactions) jointly predicted longitudinal grief. The first two models consider self-efficacy, positive selfevaluations, and their interactions, whereas the second two models consider self-efficacy, negative self-evaluations, and their interactions. In the first model, we regressed longitudinal grief simultaneously on self-efficacy, positive behavioral self-evaluation, and their interaction. We found that the two forms of self-evaluation independently predicted less grief over time: selfefficacy, $t(1,39)=-2.38, p<.05$, standardized beta $=-.56$; positive behavioral self-evaluation, $t(1,39)=-2.25, p<.05$, standardized beta $=$ -.42 (see Table 4 ). The interaction of the two predictors was not significant $(p>.10)$. In the second model, we regressed longitudinal grief on self- 
TABLE 4

Statistics for Multiple-Regression Models of Longitudinally Weighted Grief on Self-Efficacy, Other Self-Evaluations, and Their Interactions

\begin{tabular}{lccr}
\hline \multicolumn{1}{c}{ Model } & $t$ value & $(d f)$ & Standard $\beta$ \\
\hline 1. (a) Self-efficacy & $-2.38^{*}$ & $(1,39)$ & -.56 \\
(b) Positive behavioral SE & $-2.25^{*}$ & & -.42 \\
(c) Interaction of a and b & 1.32 & & .37 \\
2. (a) Self-efficacy & -1.42 & $(1,39)$ & -.40 \\
(b) Positive characterological SE & 0.20 & & .04 \\
(c) Interaction of a and b & 0.01 & & .00 \\
3. (a) Self-efficacy & $-2.26^{*}$ & $(1,38)$ & -.29 \\
(b) Negative behavioral SE (linear) & 1.48 & & .28 \\
(c) Negative behavioral SE (quadratic) & $-3.52^{* * *}$ & & -.77 \\
(d) Interaction of a and c & $3.09 * *$ & & .50 \\
4. (a) Self-efficacy & $-2.05 *$ & $(1,38)$ & -.30 \\
(b) Negative characterological SE (linear) & 1.70 & & .26 \\
(c) Negative characterological SE (quadratic) & -1.57 & & -.31 \\
(d) Interaction of a and c & -0.12 & & -.02 \\
\hline
\end{tabular}

Note. Adjusted $R^{2}$ values: Model $1=.19$, Model $2=.09$, Model $3=.33$, Model $4=.18$. $\mathrm{SE}$, self-evaluation.

$$
\begin{aligned}
* p & <.05 . \\
* * p & <.01 . \\
* * * p & <.001 .
\end{aligned}
$$

efficacy, positive characterological self-evaluation, and their interaction. We found that in this simultaneous model, none of the narrative variables predicted grief significantly. However, when not considering the interaction, self-efficacy predicted less grief over time, controlling for characterological self-evaluation, $t(1,40)=-2.66, p=.01$, standardized beta $=-.40$.

In the third model, we regressed longitudinal grief simultaneously on selfefficacy, linear and quadratic contrasts of negative behavioral self-evaluation, and the interaction of self-efficacy and quadratic negative behavioral self-evaluation. We found three independent predictors: Self-efficacy predicted significantly less grief, $t(1,38)=-2.26, p<.05$, standardized beta $=$ -.29 ; an optimal level of negative behavioral self-evaluation predicted significantly less grief, $t(1,38)=-3.52, p=.001$, standardized beta $=$ -.77 ; and the interaction of self-efficacy and the optimal level of negative behavioral self-evaluation predicted grief significantly, $t(1,38)=3.09, p<$ .01 , standardized beta $=.50$. This model accounted for $33 \%\left(\right.$ adjusted $R^{2}$ ) of the variance of grief over time. By examining group means, we found that, on average, participants who made reference to self-efficacy had lower grief levels than did those who did not, whether or not they made optimal levels of negative behavioral self-evaluations. In other words, participants 
who overtly expressed a sense of self-efficacy had statistically equivalent levels of grief whether they made no, one, or multiple negative self-evaluations. However, among participants who made no reference to self-efficacy, those who made one negative behavioral self-evaluation had less grief than did those who made either none or more than one, much as when self-efficacy was not considered in the equation. Thus, it appeared that mentioning a sense of self-efficacy overrode the ill effects of making too few or too many negative behavioral self-evaluations.

In the fourth model, we regressed longitudinal grief simultaneously on self-efficacy, the linear and quadratic contrasts of negative characterological self-evaluation, and the interaction of self-efficacy and quadratic negative characterological self-evaluation. We found that only self-efficacy predicted (less) grief significantly, $t(1,38)=-2.05, p<.05$, standardized beta $=$ -30 . However, the quadratic contrast of negative characterological self-evaluation also predicted grief significantly and independently when not considering the interaction, $t(1,39)=-2.15, p<.05$, standardized beta $=-.33$. In other words, participants who made one negative characterological selfevaluation had significantly less grief than did those who made either none or more than one, regardless of whether they mentioned a sense of selfefficacy. In contrast to the findings with negative behavioral self-evaluations, self-efficacy seemed not to mitigate the ill effects of making too few or too many negative characterological self-evaluations.

\section{Potential Confounds}

Verbosity (i.e., the total number of NUs expressed by each participant) correlated with the total number of negative characterological self-evaluations, Spearman's $r=.39, p=.001$, but not with any other self-evaluation variable. In other words, the tendency to make frequent self-evaluations was generally not related to how much participants talked. However, verbosity was significantly correlated with grief at 14 months post-loss, $r=.28, p<$ .05 , and at 25 months post-loss, $r=.32, p<.05$. In other words, people who talked more had significantly higher levels of grief at 14 and 25 months post-loss, $r s=.28$ and .32 , respectively, $p s<.05$. Most important, all of the relationships between self-evaluation and longitudinal grief retained the levels of significance reported earlier, controlling for verbosity. Two other potential confounds were considered. The DAS (which measured relationship closeness and psychological adjustment within the relationship) significantly correlated only with the total number of positive characterological self-evaluations, $r=.27, p<.05$. The DAS did not significantly moderate any of the relationships between self-evaluation and grief. Also, perceived social support did not significantly correlate with self-evaluation or significantly moderate any of the self-evaluation-grief relationships. 


\section{DISCUSSION}

In this study, we aimed to distinguish narrative evaluations of self-efficacy from other related forms of self-evaluation, with the aim of finding individual differences in psychological health during conjugal bereavement. The results generally supported our four primary predictions. First, when talking about their lives, conjugally bereaved participants did differentiate evaluations of their abilities from evaluations of actual actions and characteristics. Second, participants who made positive evaluations of their abilities (i.e., expressed self-efficacy) had lower levels of grief over time while adjusting longitudinally to conjugal bereavement, compared to those who did not express selfefficacy. Third, the relationship between grief and self-efficacy was independent of the relationships between grief and evaluations of one's actual behaviors and characteristics. Fourth, self-efficacy moderated the relationship between behavioral, but not characterological, self-evaluations and grief over time. These findings shed light not only on how self-efficacy is manifested in everyday language but also on how self-efficacy and other selfevaluations operate in relation to each other during times of crisis.

\section{Distinguishing Self-Efficacy from Other Self-Evaluations}

Our descriptive findings suggested that participants made selective use of portraying an overt sense of self-efficacy, compared to other forms of selfevaluation. In other words, participants tended to focus more on evaluations of "actual" behaviors and characteristics than on evaluations of the ability to do or be something. One reason for this was that self-efficacy was defined as a subcategory of other self-evaluations in our coding system, producing a stringent definition of self-efficacy. Statements such as "I could" or "I was able" were coded as self-efficacy only when the behaviors or characteristics in question were modified by an explicitly affect-laden evaluation. Another explanation for the selective use of self-efficacy was that the distinction between abilities and behaviors or characteristics is subtle, especially in the everyday expression of self-evaluations. According to attribution theory, observers typically assume that a person has certain abilities on hearing or seeing that the person completed an action successfully; thus, abilities are often implied by the knowledge of successful actions or characteristics. The explicit mention of one's own abilities as distinct from behaviors or characteristics in narratives points to the individual's ability to communicate (and perceive) subtle distinctions of the self. Even more infrequent were statements of self-inefficacy. As mentioned under Method, people tended to depersonalize their inabilities (e.g., by using third-person pronouns) and to emphasize the impossibility of the situation at hand, thereby hinting at selfinefficacy too indirectly to be coded.

In distinguishing self-efficacy from other self-evaluations, self-efficacy 
correlated significantly only with the total number of positive behavioral self-evaluations. Despite the fact that self-efficacy was operationally defined as a type of behavioral or characterological self-evaluation, self-efficacy was not related to any other form of self-evaluation (and notably not to positive evaluations of one's characteristics). The relationship between self-efficacy and positive evaluations of one's behavior is consonant with the common understanding that self-efficacy refers to a perceived ability to do something well. Still, the correlation between the two in our study, although significant, was not particularly strong (Spearman's $r=.26$ ). Thus, we concluded, much as predicted, that the narrative description of self-efficacy was generally, but not entirely, distinct from other forms of narrative self-evaluation.

\section{Narrative Self-Efficacy, Other Self-Evaluations, and Psychological Health}

A sense of self-efficacy in participants' narratives predicted successful long-term adaptation to conjugal bereavement, as predicted. More precisely, participants who made at least one reference to self-efficacy had significantly lower levels of grief over time than did participants who made no reference to self-efficacy. This finding extended previous reports of the adaptive qualities of self-efficacy during times of significant change or stress (Bandura, 1977, 1997; Folkman, 1984; Maddux \& Lewis, 1995). Particularly during bereavement, the sense that one is capable and strong provides a confident base for building a new life (Baumeister, 1991; Parkes \& Weiss, 1983). Selfefficacy works to minimize negative emotion during conjugal bereavement by establishing the sense that one can still function competently in various life domains and that one can still have meaningful relationships. For example, self-efficacy enables a bereaved spouse to say, "I lost my spouse but I can still do a good job at work" or "I lost my spouse but I can still keep part of that relationship alive through my relationship with my children", (Bonanno \& Kaltman, 1999). Self-efficacy, as a sense of potential, also fosters a sense of what could possibly be (i.e., a sense of hope), which is essential during times of extreme loss (Baumeister, 1991; Weiss, 1993). This sense for one's possibilities is also essential for creating the new courses of action in daily life that are necessary after a spouse's death or other life-altering crises (Bandura, 1997; Folkman, 1984; Parkes \& Weiss, 1983).

Furthermore, self-efficacy predicted less grief over time, even when controlling perceptions of actually doing well and being good. In other words, not only do people distinguish their abilities from their behaviors and characteristics in everyday narratives, but these distinctions also have implications for psychological health. These findings suggest that the relationship between self-efficacy and grief did not come about simply as a by-product of the sense that one had done things well or that one was a good person. Although self-efficacy appears to be grounded in the sense that one has done 
things well (Bandura, 1977), the current findings suggest that self-efficacy may take on a life of its own in relation to psychological health.

As for the positive self-evaluations of doing well and being good, only the former was significantly related to psychological health, supporting previous findings concerning the adaptive benefits of focusing on one's behaviors rather than on one's broader characteristics (Bauer \& Bonanno, 2001; JanoffBulman, 1992; Zirkel \& Cantor, 1990). However, a different scenario emerged for negative self-evaluation. Previously, we found that an optimal level of negative self-evaluation predicted psychological health (Bauer \& Bonanno, 2001). In other words, a limited dose of negative self-evaluation (i.e., one negative self-evaluation in a 6-min interview task) was adaptive, whereas either too few (i.e., none) or too many (i.e., two or more) negative self-evaluations was maladaptive. Those findings supported previous narrative research showing that people can actually evaluate themselves too positively for their own good or that a limited dose of negativity in narrative discourse corresponds to psychological health, provided that a sufficient dose of positivity can balance the limited negativity (Gottman, 1994; Pennebaker \& Seagal, 1999). This "mostly good, some bad" scenario may correspond to psychological health because it allows for a generally positive view of self that also has the sense of being grounded in the typical world of occasional setbacks (Bauer \& Bonanno, 2001). The current study revealed that this optimally healthy level of negative self-evaluation was equally true for both behavioral and characterological forms of self-evaluation unless the participant made reference to self-efficacy.

For those who mentioned self-efficacy, the optimally healthy level of negative behavioral self-evaluation disappeared. In other words, for those who mentioned self-efficacy, grief levels were the same whether one made no, one, or more than one negative behavioral self-evaluations. In contrast, for people who did not mention self-efficacy, the optimal level of negative selfevaluation held (i.e., grief levels were lowest for those who made one negative behavioral self-evaluation). However, self-efficacy did not moderate the relationship between negative characterological self-evaluations and grief over time. In other words, participants making a single negative characterological self-evaluation had less grief whether they expressed self-efficacy or not. Thus, although interpretations are made with caution due to group size, a sense of self-efficacy appeared to neutralize the ill effects of participants' negative evaluations of their behaviors but not of their characteristics.

Relatedly, Janoff-Bulman (1992, p. 126) found that rape victims who expressed behavioral self-blame (e.g., "I should not have gone back to his apartment') adapted better psychologically than did those who expressed characterological self-blame (e.g., "I am a very bad judge of character') (emphases added to show behavioral/characterological distinction). Janoff- 
Bulman interpreted this finding as evidence that behavioral self-blame preserved some sense that the self could have had control (i.e., self-efficacy). A person who interprets a mere action as bad (i.e., "I did badly") can also interpret the event as a temporary break in one's more general self-control (i.e., self-efficacy), thereby preserving or creating the general sense that the self is good (i.e., "I am good"). In contrast, a person who interprets the self as bad more broadly (i.e., "I am bad") will have a more difficult time using a sense of self-efficacy to preserve or create a general sense that the self is good (i.e., "I am good'"). Overall, these findings suggest that people who make negative evaluations of their behaviors either too seldom or too frequently may rely on the buffering effects of self-efficacy to maintain a course of psychological health, whereas those who make too few or too many negative evaluations of personal characteristics might not be so fortunate.

The current study also provided evidence that narrative or linguistic patterns of self-evaluation have long-term implications for psychological health. One benefit of the narrative approach is that the individual voluntarily presents his or her own system of personally valued abilities and strengths, as opposed to rating one's sense of control on an imposed array of phenomena that may or may not be an important part of the individual's life story. We do not mean to suggest the absolute superiority of the narrative approach. Indeed, because narrative and questionnaire methods derive from different assumptions and typically address different aims, the relative suitability of one method over the other will rest on the aims of the researcher and the study at hand. If the aim is to compare individual differences in the degree to which one senses control, then a questionnaire approach is perhaps most efficient. However, in this study, we aimed to examine individual differences in how people distinguish their valued abilities from their valued actions and characteristics in everyday thinking and conversation. Interview narratives approximate this context, allowing for a systematic examination of subtle distinctions in the thinking process. In reviewing the findings, it is important to keep in mind that subtle differences in the linguistic structure of selfevaluations (as revealed in the distinction of words such as can, do, and be) were the phenomena that held long-term implications for psychological health. In the course of describing themselves in everyday speech, people do not typically deliberate on their choice of these words; the decision to use one verb type over another occurs rapidly and often without awareness. While people appeared to express self-efficacy selectively-with implications for psychological health-it is unlikely that they were very aware of the degree to which they were doing so. For these reasons, we feel that the narrative study of self-evaluation affords an understanding of the underlying process of constructing meaning and identity in ways that correspond to psychological health. Furthermore, narrative inquiry of this sort also aims to 
contribute to an understanding of narrative structure itself (i.e., how people tell their life stories).

\section{Other Considerations}

As for the longitudinal aspect of this study, it is important to keep in mind that narrative patterns of self-evaluation were made at 6 months post-loss and that these patterns predicted grief at 6, 14, and 25 months post-loss. We feel that these longitudinal relationships likely reflected the fact that we addressed self-efficacy and self-evaluation in terms of identity construction generally rather than in terms of coping or adjustment to loss specifically. We were interested in the types of self-evaluation that, when viewed in patterns over a narrative, reflect structural dimensions of how people create a sense of self-identity and not how they adapt to change. Thus, we expected that the participants' sense of self-efficacy (along with the other forms of self-evaluation) would predict how well they adapted in the long run. In fact, we found that self-efficacy predicted less grief during the second and third measurement periods but not during the first. This finding indicated to us that these narrative patterns of self-efficacy, although expressed at 6 months post-loss, reflected long-term patterns of psychological health rather than the immediate fluctuations of psychological health due to the loss. We also found that none of the self-evaluation patterns interacted with time in predicting grief (i.e., we found main effects but no group by time interactions). We feel that the lack of group by time interactions also results from our phenomena of interest and our operational definitions. If we had aimed to examine selfevaluation patterns relating specifically to adjustment to loss, then we would have expected to find differences not only in the degree of grief over time (which we did find) but also in the course of grief over time (which we did not find). The fact that grief decreased over time at the same rate for all self-evaluation groups indicates that individual differences in self-evaluation related to differences in psychological health generally, which is more specifically what we aimed to measure. In addition, the relationships between narrative self-evaluation and grief were not altered significantly by either verbosity, perceived relationship closeness, or perceived social support.

Several limitations are worthy of consideration. First, as mentioned earlier, the frequency with which participants referred to self-efficacy was low, due in part to the stringent criteria of the coding system. Only the most conspicuous references to abilities, strength, or control were coded for self-efficacy. Indeed, many times coders noted that a particular phrase seemed to be about efficacy, but the phrase was not coded for self-efficacy because the criteria for overtness were not met. Certainly, future research on narrative self-efficacy (perhaps with less stringent, yet still reliable, operational definitions) is needed to understand both the prevalence of self-efficacy in life stories 
and its relation to psychological health. Second, these narratives were coded in terms of basic dimensions of self-evaluation rather than in terms of coping with the death of a spouse. Thus, our narrative constructs did not address bereavement specifically, meaning that we probably found out more about self-efficacy and psychological health generally than about bereavement in particular. Conversely, we did find that adjustment to bereavement did conform to the more general theoretical principles of self-efficacy and self-evaluation. Third, these narratives were generated in the context of describing the spousal relationship and not the life of the participant as an individual (or the individual's health or coping status). We would expect that different questions (e.g., relating to abilities) would yield different information about the role of self-efficacy as a form of self-evaluation. Finally, this study was correlational by design, and we do not mean to claim that these narrative patterns of self-efficacy caused lower grief levels. However, possible confounding (and causal) variables, such as perceived relationship closeness and perceived social support, were not significant factors in the self-evaluationgrief relationships. Also, we point out that particular patterns of interpreting one's life do underlie both the tendency to make self-evaluations in particular ways and the tendency to adapt well during stressful life changes (Baumeister, 1991; Folkman, 1984; Janoff-Bulman, 1992; McAdams, 1993). The narrative study of self-evaluation, although not equivalent to the interpretation process, reflects key dimensions of it.

\section{CONCLUSION}

With this study, we hoped to shed light on how self-efficacy, as a unique form of self-evaluation, is constructed in the stories that people tell about their lives, notably when people are not directed to think specifically about issues of abilities, strength, and control. We found that the participants did think about their abilities differently from their actual behaviors and characteristics and that these differences had implications for psychological health. The presence of self-efficacy in personal narratives predicted successful adaptation to bereavement longitudinally, over and beyond the effects of other types of self-evaluation and in certain cases counterbalancing the ill effects of negative self-evaluation. In short, spontaneously saying simple things such as "I can do well" and "I can be good" was especially suggestive of healthy psychological adjustment to the death of a spouse. Furthermore, the seemingly subtle difference between statements such as "I can do well" and "I do well" ' had distinct and complex implications for that adjustment. We hope that these findings are useful for future work in narrative, personality, social, and clinical psychology. 


\section{APPENDIX}

\section{Examples of Self-Evaluations and Other Statements}

Positive self-evaluation
Negative self-evaluation

\section{Behavioral}

"We liked going to the movies."

"I think I made her successful.,"

Characterological

"I'm the best salesman.,"

"We had a great marriage.",

\section{Self-efficacy}

"I was able to help her when she needed me."

"We could do anything we wanted.",

\section{Behavioral}

"We hated spending time together.",

"I think I caused her to fail.,"

\section{Characterological}

"I'm a bad salesman."

"We had a horrible marriage.,"

Self-inefficacy

"I just couldn't give what she needed."

"We never had control over our lives."

Other Statements
Nonevaluative self-description
"We were married 15 years.",
"We went to the movies a lot.",
Nonself-evaluation
"Marriage is a good thing.",
"It's been an awful year.,"

\section{REFERENCES}

Arbuckle, N. W., \& de Vries, B. (1995). The long-term effects of later life spousal and parental bereavement on personal functioning. The Gerontologist, 35, 637-647.

Armitage, C. J., \& Conner, M. (1999). Distinguishing perceptions of control from self-efficacy: Predicting consumption of a low-fat diet using the theory of planned behavior. Journal of Applied Social Psychology, 29, 72-90.

Bandura, A. (1977). Self-efficacy: Toward a unifying theory of behavioral change. Psychological Review, 84, 191-215.

Bandura, A. (1997). Self-efficacy: The exercise of control. New York: Freeman.

Bandura, A., Pastorelli, C., Barbaranelli, C., \& Caprara, G. V. (1999). Self-efficacy pathways to childhood depression. Journal of Personality and Social Psychology, 76, 258-269.

Bauer, J. J., \& Bonanno, G. A. (2001). Doing and being well (for the most part): Adaptive patterns of narrative self-evaluation during bereavement. Journal of Personality, 69, 451482.

Baumeister, R. F. (1991). Meanings of life. New York: Guilford.

Baumeister, R. F., \& Newman, L. S. (1994). How stories make sense of personal experiences: Motives that shape autobiographical narratives. Personality and Social Psychology Bulletin, 20, 676-690.

Bonanno, G. A., \& Kaltman, S. (1999). Toward an integrative perspective on bereavement. Psychological Bulletin, 125, 760-776.

Bonanno, G. A., \& Keltner, D. (1997). Facial expressions of emotion and the course of bereavement. Journal of Abnormal Psychology, 106, 126-137.

Bonanno, G. A., Keltner, D., Holen, A., \& Horowitz, M. J. (1995). When avoiding unpleasant emotions might not be such a bad thing: Verbal-autonomic response dissociation and midlife conjugal bereavement. Journal of Personality and Social Psychology, 69, 975989. 
Butterworth, B. (1975). Hesitation and semantic planning in speech. Journal of Psycholinguistic Research, 4, 75-87.

Campbell, D. T., \& Fiske, D. W. (1959). Convergent and discriminant validation by the multitrait-multimethod matrix. Psychological Bulletin, 56, 81-106.

Cantor, N. (1990). From thought to behavior: "Having" and "doing" in the study of personality and cognition. American Psychologist, 45, 735-750.

Diener, E. (1984). Subjective well-being. Psychological Bulletin, 95, 542-575.

Diener, E., \& Fujita, F. (1995). Resources, personal strivings, and subjective well-being: A nomothetic and idiographic approach. Journal of Personality and Social Psychology, 68, 926-935.

Diener, E., Suh, E. M., Lucas, R. E., \& Smith, H. L. (1999). Subjective well-being: Three decades of progress. Psychological Bulletin, 125, 276-302.

Epel, E. S., Bandura, A., \& Zimbardo, P. G. (1999). Escaping homelessness: The influences of self-efficacy and time perspective on coping with homelessness. Journal of Applied Social Psychology, 29, 575-596.

Erikson, E. H. (1959). Identity and the life cycle. New York: Norton.

Florian, V., Mikulincer, M., \& Taubman, O. (1995). Does hardiness contribute to mental health during a stressful real-life situation? The roles of appraisal and coping. Journal of Personality and Social Psychology, 68, 687-695.

Folkman, S. (1984). Personal control and stress and coping processes: A theoretical analysis. Journal of Personality and Social Psychology, 46, 839-852.

Gottman, J. (1994). Why marriages succeed or fail. New York: Fireside.

James, W. (1890/1950). Principles of psychology. New York: Dover.

Janoff-Bulman, R. (1992). Shattered assumptions: Towards a new psychology of trauma. New York: Free Press.

Judd, C. M., \& McClelland, G. H. (1989). Data analysis: A model-comparison approach. San Diego: Harcourt Brace Jovanovich.

Judd, C. M., McClelland, G. H., \& Smith, E. R. (1996). Testing treatment by covariate interactions when treatment varies within subjects. Psychological Methods, 1, 366-378.

Kessler, R. C., Kendler, K. S., Heath, A., Neale, M. C., \& Eaves, L. J. (1992). Social support, depressed mood, and adjustment to stress: A genetic epidemiological investigation. Journal of Personality and Social Psychology, 62, 257-272.

Kessler, R. C., \& MacLeod, J. D. (1985). Social support and mental health in community samples. In S. Cohen \& S. L. Syme (Eds.), Social support and health (pp. 219-240). San Diego: Academic Press.

Lachman, M. E., \& Weaver, S. L. (1998). The sense of control as a moderator of social class differences in health and well-being. Journal of Personality and Social Psychology, 74, $763-773$.

Langer, E. J., \& Roth, J. (1975). Heads I win, tails it's chance: The illusion of control as a function of the sequence of outcomes in a purely chance task. Journal of Personality and Social Psychology, 32, 951-955.

Maddux, J. E., \& Lewis, J. (1995). Self-efficacy and adjustment: Basic principles and issues. In J. E. Maddux (Ed.), Self-efficacy, adaptation, and adjustment: Theory, research, and application (pp. 37-68). New York: Plenum.

Major, B., Richards, C., Cooper, M. L., Cozzarelli, C., \& Zubek, J. (1998). Personal resilience, cognitive appraisals, and coping: An integrative model of adjustment to abortion. Journal of Personality and Social Psychology, 74, 735-752. 
Manstead, A. S. R., \& van Eekelen, S. A. M. (1998). Distinguishing between perceived behavioral control and self-efficacy in the domain of academic achievement intentions and behaviors. Journal of Applied Social Psychology, 28, 1375-1392.

McAdams, D. P. (1985). Power, intimacy, and the life story: Personological inquiries into identity. New York: Guilford.

McAdams, D. P. (1993). The stories we live by: Personal myths and the making of the self. New York: Morrow.

McGregor, I., \& Little, B. R. (1998). Personal projects, happiness, and meaning: On doing well and being yourself. Journal of Personality and Social Psychology, 74, 494-512.

Mergenthaler, E., \& Stinson, C. H. (1992). Psychotherapy transcription standards. Psychotherapy Research, 2, 125-142.

Ogilvie, D. M. (1987). Life satisfaction and identity structure in late middle-aged men and women. Psychology and Aging, 2, 217-224.

Parkes, C. M., \& Weiss, R. S. (1983). Recovery from bereavement. New York: Basic Books.

Pennebaker, J. W., \& Seagal, J. D. (1999). Forming a story: The health benefits of narrative. Journal of Clinical Psychology, 55, 1243-1254.

Robitschek, C., \& Kashubeck, S. (1999). A structural model of parental alcoholism, family functioning, and psychological health: The mediating effects of hardiness and personal growth orientation. Journal of Counseling Psychology, 46, 159-172.

Ross, L., Amabile, T. M., \& Steinmetz, J. L. (1977). Social roles, social control, and biases in social-perception processes. Journal of Personality and Social Psychology, 35, 485494.

Ryff, C. D., \& Singer, B. (1998). The contours of positive human health. Psychological Inquiry, 9, 1-28.

Singer, J. A., \& Salovey, P. (1993). The remembered self: Emotion and memory in personality. New York: Free Press.

Spanier, G. B. (1976). Measuring dyadic adjustment: New scales for assessing the quality of marriage and similar dyads. Journal of Marriage and the Family, 38, 15-28.

Stinson, C. H., Milbrath, C., Reidbord, S. P., \& Bucci, W. (1994). Thematic segmentation of psychotherapy transcripts for convergent analysis. Psychotherapy, 31, 36-48.

Stroebe, W., \& Stroebe, M. S. (1993). Determinants of adjustment to bereavement in younger widows and widowers. In M. S. Stroebe, W. Stroebe, \& R. O. Hansson (Eds.), Handbook of bereavement: Theory, research, and intervention. Cambridge, UK: Cambridge Univ. Press.

Taylor, S. E., \& Brown, J. D. (1988). Illusion and well-being: A social psychological perspective on mental health. Psychological Bulletin, 103, 193-210.

Taylor, S. E., \& Brown, J. D. (1994). Positive illusions and well-being revisited: Separating fact from fiction. Psychological Bulletin, 116, 21-27.

Weiss, R. S. (1993). Loss and recovery. In M. S. Stroebe, W. Stroebe, \& R. O. Hansson (Eds.), Handbook of bereavement: Theory, research, and intervention. Cambridge, UK: Cambridge Univ. Press.

Wortman, C. B., \& Silver, R. C. (1990). Successful mastery of bereavement and widowhood: A life-course perspective. In P. B. Baltes \& M. M. Baltes (Eds.), Successful aging: Perspectives from the behavioral sciences. Cambridge, UK: Cambridge Univ. Press.

Zirkel, S., \& Cantor, N. (1990). Personal construal of life tasks: Those who struggle for independence. Journal of Personality and Social Psychology, 58, 172-185. 